\title{
Poor sitting posture and a heavy schoolbag as contributors to musculoskeletal pain in children: an ergonomic school education intervention program
}

\author{
This article was published in the following Dove Press journal: \\ Journal of Pain Research \\ 13 September 2011 \\ Number of times this article has been viewed
}

\author{
Al Syazwan' \\ MN Mohamad Azhar' \\ AR Anita' \\ HS Azizan' \\ MS Shaharuddin² \\ J Muhamad Hanafiah ${ }^{3}$ \\ AA Muhaimin ${ }^{4}$ \\ AM Nizar ${ }^{5}$ \\ B Mohd Rafee ${ }^{1,6}$ \\ A Mohd Ibthisham ${ }^{7}$ \\ Adam Kasani ${ }^{7}$
}

'Environmental and Occupational Medicine Unit, Department of Community Health, Faculty of Medicine and Health Sciences, Universiti Putra Malaysia, Serdang, Selangor, Malaysia; ${ }^{2}$ Environmental and Occupational Health Unit, Department of Community Health, Faculty of Medicine and Health Sciences, Universiti Putra Malaysia, Serdang, Selangor, Malaysia; ${ }^{3} \mathrm{Health}$ Services Management Unit, Department of Community Health, Faculty of Medicine and Health Sciences, Universiti Putra Malaysia, Serdang, Selangor, Malaysia; ${ }^{4}$ Department of Environmental Management, Faculty of Environmental Studies, Universiti Putra Malaysia, Serdang, Selangor, Malaysia; ${ }^{5}$ Pharmacology Unit, Department of Human Anatomy, Faculty of Medicine and Health Sciences, Universiti Putra Malaysia, Serdang, Selangor, Malaysia; ${ }^{6}$ Ergonomic Division, National Institute of Occupational Safety and Health Bangi, Selangor, Malaysia; ${ }^{7}$ Department of Mechanical Engineering, Faculty of Mechanical Engineering, Universiti Teknologi Malaysia, Skudai, Johor, Malaysia

Correspondence: Aizat Ismail Syazwan Environmental and Occupational Medicine Unit, Department of Community Health, Faculty of Medicine and Health Sciences, Universiti Putra Malaysia, 43400

Serdang, Selangor, Malaysia

Tel +603 89472358

Fax +60389472395

Email syazwan@medic.upm.edu.my
Objectives: The purpose of this study was to evaluate a multidisciplinary, interventional, ergonomic education program designed to reduce the risk of musculoskeletal problems by reducing schoolbag weight and correcting poor sitting posture.

Methods: Data were collected twice before and twice following intervention using the Standardized Nordic Body Map Questionnaire, a rapid upper limb assessment for posture evaluation, and schoolbag weight measurement in children aged 8 and 11 years attending two schools within the central region of Malaysia.

Results: Students who received the ergonomic intervention reported significant improvements in their sitting posture in a classroom environment and reduction of schoolbag weight as compared with the controls.

Conclusion: A single-session, early intervention, group ergonomics education program for children aged 8 and 11 years is appropriate and effective, and should be considered as a strategy to reduce musculoskeletal pain among schoolchildren in this age group.

Keywords: ergonomic, education, intervention, assessment, musculoskeletal pain, school children, awareness

\section{Introduction}

Workstations in schools may contribute to musculoskeletal pain in school-aged children. During classroom lessons, children often sit with poor posture, having their trunk, back, and neck flexed or rotated for long periods, ${ }^{1-3}$ with musculoskeletal pain arising from the classroom environment. In Malaysia, ergonomic issues have not been widely addressed or documented among schoolchildren compared with other issues, such as air quality, ${ }^{4,5}$ water pollution, ${ }^{6,7}$ food safety, and other physical hazards in schools. ${ }^{8}$

According to the Hazard Identification Risk Assessment and Risk Control study by Nurul, ${ }^{9}$ universal factors that influence the incidence of musculoskeletal pain in schoolchildren can be divided into three groups, ie, a heavy schoolbag (weighing more than $10 \%$ of body weight), ${ }^{10-12}$ a furniture design that does not suit human body dimensions, and incorrect sitting posture on the part of the children themselves. Although musculoskeletal pain is believed to be caused by multiple factors, the school environment is an important factor, because children spend about $30 \%$ of their time in school, especially in the sitting position. ${ }^{9,13}$ When posture is affected by an awkward body position while sitting or when lifting a heavy school bag, the musculoskeletal system is compromised. ${ }^{8,14}$ 
Previous studies suggest that another potential contributor to nonspecific low back pain is the time spent sitting on poorly designed furniture (awkward position and prolonged sitting with a lack of exercise), as reported by Balague et al, ${ }^{15}$ Yeats, ${ }^{16}$ and Troussier et al. ${ }^{17}$ Other factors reported to cause musculoskeletal pain are high body mass index, ${ }^{18}$ psychosomatic illness, ${ }^{19-21}$ and low levels of physical activity. ${ }^{22,23}$

Some of the aforementioned risks have been investigated by previous researchers, ${ }^{8}$ with recommendations made to develop future intervention strategies for reducing these risks. Intervention programs that have been considered previously include use of ergonomic furniture, ${ }^{24}$ health promotion packages, ${ }^{21}$ and exercises to reduce muscle fatigue. ${ }^{25,26}$ Studies of risk factor reduction have mentioned intervention programs to reduce schoolbag weight and advocated the use of engineering methods to modify furniture to a more ergonomic design which could significantly reduce the risk of awkward posture while sitting. ${ }^{8}$ However, when reviewing the ergonomics literature, no extensive descriptions or evaluations were found for primary community-based early intervention or prevention strategies for children's sitting problems, although many investigators have supported the recommendations for such strategies. ${ }^{8,25-28}$ The purpose of this investigation was to evaluate the effectiveness of two sessions of a basic educational training program emphasizing exercise for reducing ergonomic risk factors contributing to musculoskeletal pain in children aged 8 and 11 years.

\section{Methods}

This nonrandomized study evaluated a multidisciplinary, community-based intervention, ie, the Ergonomic Health Promotion Program (EHPP), in schoolchildren aged 8 and 11 years. We used a quasi-experimental time series design consisting of an experimental group $(n=78)$ and a control group $(n=75)$, with multiple observations made before and after treatment. In this study, measurement of dependent variables occurred at two points in time prior to the intervention and at two points in time after the intervention.

\section{Sample and setting}

A convenience sample of 153 children with consenting parents from two schools was recruited for this study, which was undertaken in Seri Kembangan and Serdang, Selangor, Malaysia. The city of Selangor is situated in southern Kuala Lumpur and is the third largest local government area within Malaysia, with an estimated resident population of over 120,000 inhabitants. Two study groups were formed, comprising a group from Seri Kembangan school as the experimental group and the other from Serdang school as the control group. The target study population was children aged 8 and 11 years who were attending either of these two schools. Ethical approval was obtained from the Medical Research Ethics Committee at the Universiti Putra Malaysia, and informed written consent from guardians or parents was obtained for all participants in the study.

\section{Questionnaires}

All students from the experimental and control groups were given a two-part questionnaire to complete at baseline. Section 1 contained questions concerning their sociodemographic background, including ethnicity, method of transportation to school, type of school bag, and home activities. Section 2 contained questions concerning ergonomic risk factors and the Standardized Nordic Body Map Questionnaire (SNBMQ). ${ }^{29}$ This questionnaire shows a body diagram consisting of nine body parts, ie, neck, shoulder, upper back, lower back, elbow, arm, hand, thigh, knee, and leg, to assist the students in identifying the correct body parts when answering the questions. The SNBMQ contained questions regarding musculoskeletal pain lasting for 1 month or 7 days. During the postintervention assessments, the same SNBMQ was used for both groups. The data for musculoskeletal symptoms reported by this group have been published elsewhere. ${ }^{25}$

An ergonomics awareness test was done for all respondents to evaluate their knowledge concerning ergonomic hazards before and at the end of the intervention program. The ergonomics awareness test consisted of questions regarding knowledge of risk factors for musculoskeletal pain, eg, "Do you know how to sit on your chair?" Each ergonomics awareness test question was developed based on the key item for testing basic student knowledge about the item discussed in the intervention. The questions were closed, with two choices given (ie, $\mathrm{A}=$ yes, $\mathrm{B}=$ no), and the answers were recorded on visual mark recognition answer sheets, given to both the experimental and control groups. For each correct answer, a score of 1 was given. The total score for the ergonomics awareness test was 31 , and correct questions were then calculated as a percentage of total questions set as the denominator.

A rapid upper limb assessment (RULA) was then carried out to evaluate posture without informing the students, in order to avoid a "healthy subject effect", whereby a subject may pretend to have good posture when the assessment 
is made, but at the end of the study period be found to have poor posture. The RULA was performed by a trained observer according to the method described by McAtamney and Corlett. ${ }^{30}$

Schoolbag weights were then measured during the preintervention phase. The weight of each subject's schoolbag (including everything brought to school on the day of measurement, eg, water bottle, books, stationery, and food) was measured using an electronic Tanita weighing scale Model SECA 872 with an accuracy of $\pm 0.1 \mathrm{~kg}$. The researcher did not inform the students before performing the schoolbag weight determination, to avoid changes in the pattern of schoolbag weight.

\section{EHPP intervention}

The EHPP intervention comprised a single-session, halfhour education program administered by a trained instructor covering strategies to minimize childhood musculoskeletal pain. The EHPP consists of a poster, pamphlet, flyers, and a compact disc with a short documentary video on ergonomics and several short exercises to reduce ergonomic risk factors for musculoskeletal pain (Figure 1). The exercises comprise stretching techniques when seated in the chair and when resting in the morning, with repetition of each exercise 10-16 times. Further exercise steps are described elsewhere. ${ }^{8}$

The EHPP program was developed following initial identification of risk factors. ${ }^{8}$ The content of the documentary video includes: prevalence of musculoskeletal pain among schoolchildren; risk factors for musculoskeletal pain among schoolchildren; optimal ergonomic seating posture in existing furniture; exercises and stretching (when seated in the chair and during recess), with each exercise requiring 10-16 repetitions; and correct lifting techniques. The video is in the Malay language and uses graphics, animations, screen titles, and narration to convey this information. To determine whether changes as a result of the intervention (risk reduction rate, ie, knowledge, posture score, and bag weight) were due to the EHPP program, a control group which did not undergo an ergonomic risk intervention strategy was included.

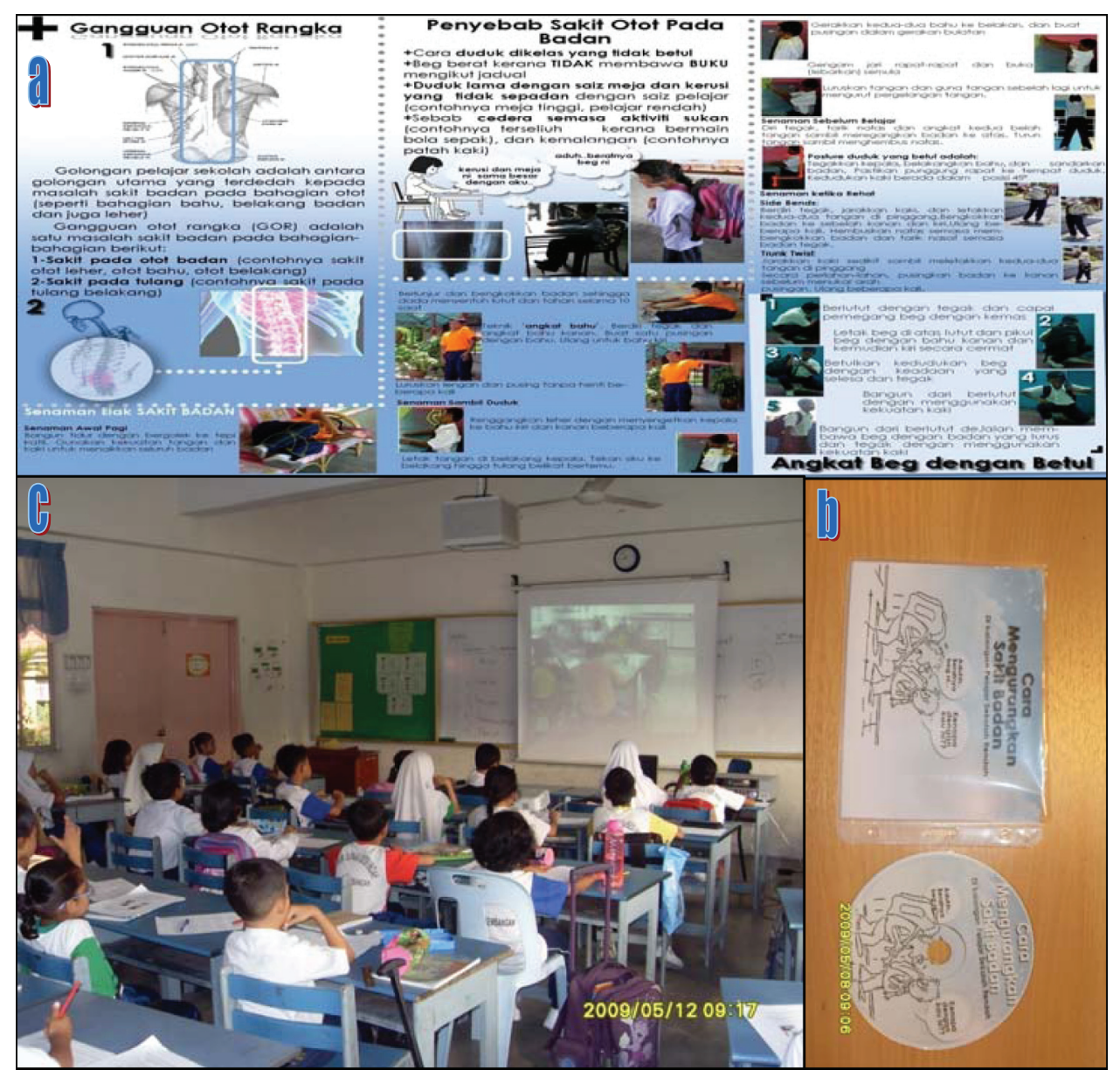

Figure I Ergonomic health promotion package. (a) Pamphlet, (b) video compact disc, and (c) exercise and training session. 


\section{Data collection}

After collection of the preintervention data, two interventions were carried out within a month of each other (Figure 2). Each intervention was followed by two assessments, conducted within a month of each intervention. The first item in each assessment was the ergonomic awareness test on risk factors in the school environment, and was distributed to both the experimental and control groups.

The second item was the RULA checklis ${ }^{30}$ to assess the children's posture in the classroom. A set of digital video recordings was used to record the posture of the children at randomly selected times during the week-long period of assessment. Simple random sampling was used to select a subsample of students from each class for the RULA posture assessment. ${ }^{8}$ For this assessment, the children were observed individually for an average of 15 minutes in the classroom. The RULA checklist was translated into the Malay language, with numerical scores recorded. Good interreliability results were obtained (Cronbach's alpha $=0.8120$ for arm, 0.7951 for wrist, 0.7851 for neck, 0.8141 for trunk, and 0.8310 for leg).

The third item was determination of schoolbag weight, which was done at both the first and second assessment times. Additional information regarding musculoskeletal pain was also gathered during the study period. The SNBMQ assessment focused on musculoskeletal pain reported in the previous 7 days. This intervention and assessment program is shown in graphic form in Figure 2.

\section{Statistical analysis}

Data for the SNBMQ, ergonomic awareness test, RULA, and schoolbag weight were entered into the Statistical Package for Social Sciences version 17.0 (SPSS Inc, Chicago, IL). Descriptive analyses using visual and numerical summaries and measures of central tendency were performed on the demographic data to describe the sample characteristics. Inferential statistics, including paired $t$-tests, repeatedmeasures analysis of variance, a general linear model, and Chi-square tests, were used to test the hypothesis that improvements in children's sitting posture and schoolbag weight would reduce reports of musculoskeletal pain. A $P$ value of $<0.05$ was considered to be statistically significant.

\section{Results \\ Demographic characteristics}

A total of 153 children were enrolled in the study and completed the SNBMQ 1 month before the intervention. Of these, 78 attended the EHPP program and 75 completed the SNBMQ, and all underwent these assessments at the two data collection points. No significant differences were found in the demographic profiles for the two groups (see Table 1). Table 2 shows the inferential statistical tests used to evaluate the experimental and control groups, which showed no differences in the study variables between the experimental control groups, except for schoolbag weight in students aged 11 years. Table 3 shows the lifetime prevalence of musculoskeletal pain, reported most commonly in the neck, shoulders, and legs.

\section{Reports of musculoskeletal pain}

Results of the SNBMQ analyzed over time (at baseline, and first and second assessments) are shown in Table 4. There was no significant reduction in reports of neck, elbow, arm, upper back, hip, thigh, and leg pain in the experimental group. There was also no significant change in pain reported by the control group, except for increased reports of neck pain.

\section{Changes in study variables in 8-year-old students}

Results from the repeated-measures general linear model show that the experimental group had a significant increase in ergonomic awareness test scores between the first and second assessments. However, the 8-year-old students showed a slight decrease in their ergonomic awareness test scores at the second assessment (Figure 3). No positive changes (ie, increasing knowledge) were seen in the control group for ergonomic awareness test scores. There was a significant reduction in schoolbag weight at the second assessment.

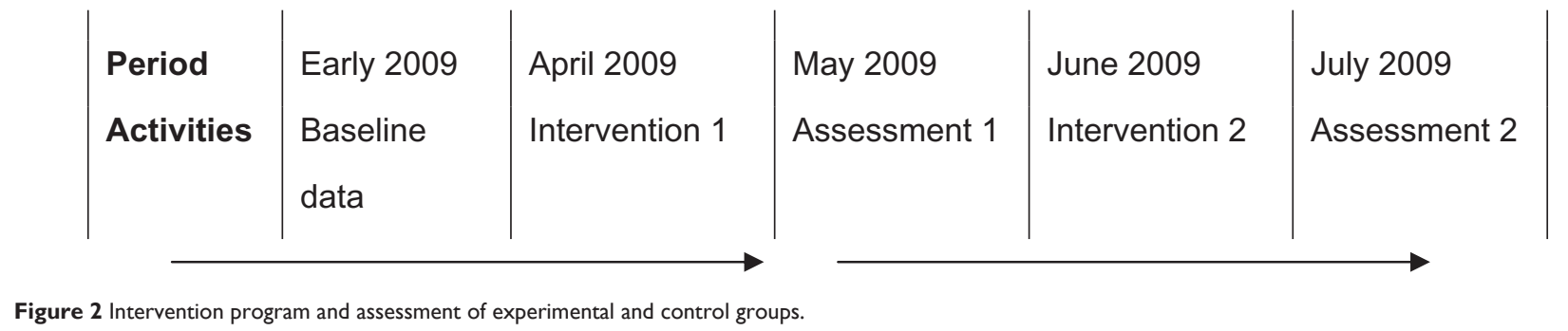


Table I Sociodemographic characteristics of experimental and control groups

\begin{tabular}{|c|c|c|c|c|}
\hline Characteristic & $\begin{array}{l}\text { Experimental } \\
(\%)^{a}\end{array}$ & $\begin{array}{l}\text { Control } \\
(\%)^{b}\end{array}$ & $\chi^{2}$ & $P$ value \\
\hline \multicolumn{5}{|l|}{ Gender } \\
\hline Male & $31(39.7)$ & $32(42.7)$ & 0.135 & 0.713 \\
\hline Female & $47(60.3)$ & $43(57.3)$ & & \\
\hline \multicolumn{5}{|l|}{ Race } \\
\hline Malay & $56(71.8)$ & $73(97.3)$ & $\mathrm{N} / \mathrm{A}^{*}$ & $\mathrm{~N} / \mathrm{A}^{*}$ \\
\hline Chinese & $2(2.6)$ & $2(2.7)$ & & \\
\hline Indian & $16(20.5)$ & - & & \\
\hline Others & $4(5.1)$ & - & & \\
\hline \multicolumn{5}{|c|}{ Transportation to school } \\
\hline Walking & 77 (98.7) & $73(97.3)$ & 0.381 & 0.537 \\
\hline Using transport & $\mathrm{I}(\mathrm{I} .3)$ & $2(2.7)$ & & \\
\hline \multicolumn{5}{|c|}{ Perception of schoolbag weight } \\
\hline Not heavy & II (I4.I) & $12(16.0)$ & 0.108 & 0.743 \\
\hline Heavy & $67(85.9)$ & $63(84.0)$ & & \\
\hline \multicolumn{5}{|l|}{ Type of bag } \\
\hline Backpack & $69(88.5)$ & $64(85.4)$ & 2.516 & 0.284 \\
\hline Trolley type & $9(11.5)$ & II (I4.6) & & \\
\hline \multicolumn{5}{|c|}{ Follows school schedule } \\
\hline Yes & $72(92.3)$ & $67(89.3)$ & 0.407 & 0.524 \\
\hline No & $6(7.7)$ & $8(10.7)$ & & \\
\hline \multicolumn{5}{|c|}{ Brings food/drink in schoolbag } \\
\hline Yes & $66(84.6)$ & $60(80.0)$ & 0.560 & 0.454 \\
\hline No & $12(15.4)$ & $12(20.0)$ & & \\
\hline \multicolumn{5}{|c|}{ Perception of chair } \\
\hline Comfort & $58(74.4)$ & $61(81.3)$ & 1.076 & 0.300 \\
\hline Discomfort & $20(25.6)$ & $14(18.7)$ & & \\
\hline \multicolumn{5}{|c|}{ Perception of desk } \\
\hline Comfort & $60(76.9)$ & $64(85.3)$ & 1.761 & 0.185 \\
\hline Discomfort & $18(23.1)$ & II (14.7) & & \\
\hline \multicolumn{5}{|l|}{ Sport injury } \\
\hline Yes & $9(11.5)$ & $17(22.7)$ & 3.357 & 0.067 \\
\hline No & $69(88.5)$ & $58(77.3)$ & & \\
\hline
\end{tabular}

Notes: ${ }^{a} n=78,{ }^{b} n=75$; *violates the Chi-square contingency table.

However, the control group had a lower mean baseline schoolbag weight than the experimental group (Figure 4). RULA scores for body posture decreased significantly in the experimental group but did not decrease in the control group. This indicates that sitting posture had improved in the experimental group, while higher RULA scores were recorded in the control group (Figure 5).

\section{Changes in study variables in II-year-old students}

The ergonomic awareness test score increased during the study period in the 11-year-old students in the experimental group, but no statistically significant changes occurred in students from the control group (Figure 6). Schoolbag weight decreased significantly in the experimental group at the first assessment. However, there was no further reduction seen at the second assessment. In contrast, the control group showed
Table 2 Baseline data collection for risk element among experimental and control groups

\begin{tabular}{llll}
\hline Variables & Experimental & Control & Student's t-test \\
\hline & Age 8 years & & \\
EAT & $52.58(7.32)$ & $52.22(10.64)$ & -0.638 \\
RULA & $5.28(0.43)$ & $5.50(0.50)$ & 0.819 \\
Bag weight & $4.79(0.98)$ & $4.57(1.31)$ & -1.494 \\
& Age II years & & \\
EAT & $53.27(7.08)$ & $52.10(7.25)$ & 0.659 \\
RULA & $5.45(0.59)$ & $5.25(0.34)$ & 0.696 \\
Bag weight & $5.86(1.22)$ & $4.66(1.24)$ & $4.718^{*}$ \\
\hline
\end{tabular}

Note: *Significant at $P<0.05$.

Abbreviations: EAT, ergonomics awareness test; RULA, rapid upper limb assessment.

no changes in schoolbag weight (Figure 7). A significant reduction in RULA scores was observed in the experimental group at the first assessment, and a further reduction at the second assessment. In contrast, increasing RULA scores were recorded in the control group at both assessments (Figure 8).

\section{Discussion}

\section{Ergonomic awareness test}

This study evaluated changes in student awareness of ergonomic risks after introduction of an intervention program. In this study, the children's knowledge scores varied within the groups, ie, in those children aged 8 and 11 years and in the experimental and control groups. Scores improved significantly in the experimental group after intervention, showing progressively increasing knowledge of ergonomic risks in schools. From this study, it can be seen that awareness in children can be increased using a health promotion package and modification of their environment. Moreover, when the

Table 3 Lifetime positive reported prevalence of musculoskeletal pain

\begin{tabular}{|c|c|c|c|c|}
\hline \multirow[t]{2}{*}{$\begin{array}{l}\text { Anatomical } \\
\text { section }\end{array}$} & \multicolumn{2}{|c|}{$\begin{array}{l}\text { Lifetime prevalence } \\
\text { positive frequency (\%) }\end{array}$} & \multirow[t]{2}{*}{ Total $^{\mathrm{a}}$} & \multirow[t]{2}{*}{ Chi $\left(\chi^{2}\right)^{b}$} \\
\hline & $\begin{array}{l}\text { Experimental } \\
(n=78)\end{array}$ & $\begin{array}{l}\text { Control } \\
(n=75)\end{array}$ & & \\
\hline Neck & $15(19.2)$ & $26(34.7)$ & 41 & $4.644^{*}$ \\
\hline Shoulder & 14 (17.9) & $25(33.3)$ & 39 & $4.765^{*}$ \\
\hline Elbow & $5(6.4)$ & II (I4.7) & 16 & 2.783 \\
\hline Arm & $9(11.5)$ & $14(18.7)$ & 23 & $1.52 \mid$ \\
\hline Upper back & $8(10.3)$ & $13(17.3)$ & 21 & 1.617 \\
\hline Lower back & $8(10.3)$ & II (14.7) & 19 & 0.648 \\
\hline Hip and thigh & $8(10.3)$ & $10(13.3)$ & 18 & 0.349 \\
\hline Knee & $5(6.4)$ & II (I4.7) & 16 & 2.783 \\
\hline Leg & $8(10.3)$ & $19(25.3)$ & 27 & $5.98 I^{*}$ \\
\hline
\end{tabular}

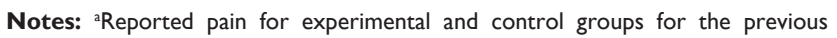
12 months; ${ }^{b} \mathrm{Chi}$-square test for test of independence (differences analysis between experimental and control group); *significant at $P<0.05$. 
Table 4 Symptoms reported by schoolchildren at baseline and at the first and second assessments

\begin{tabular}{|c|c|c|c|c|c|c|}
\hline \multirow[t]{3}{*}{ Variables } & \multicolumn{6}{|c|}{ Positive prevalence of anatomical section frequency (\%) } \\
\hline & \multicolumn{2}{|l|}{ Baseline } & \multicolumn{2}{|l|}{ Assessment I } & \multicolumn{2}{|l|}{ Assessment 2} \\
\hline & Experimental & Control & Experimental & Control & Experimental & Control \\
\hline Neck & $15(19.2)$ & $26(34.7)$ & $13(16.9)^{\mathrm{a}}$ & $30(40.0)$ & $12(15.8)^{\mathrm{a}}$ & $22(29.3)^{\mathrm{b}}$ \\
\hline Shoulder & $14(17.9)$ & $25(33.3)$ & $13(16.9)$ & $21(28.0)$ & II (14.3) & $16(21.3)$ \\
\hline Elbow & $5(6.4)$ & II (14.7) & $3(3.9)^{\mathrm{a}}$ & $14(18.7)$ & $2(2.6)$ & $19(25.3)$ \\
\hline Arm & $9(11.5)$ & $14(18.7)$ & $5(6.5)^{\mathrm{a}}$ & $15(20.0)$ & $2(2.7)^{\mathrm{a}}$ & $19(25.3)$ \\
\hline Upper back & $8(10.3)$ & $13(17.3)$ & $8(10.3)$ & 14 (I8.7) & $3(4 . I)^{\mathrm{a}}$ & $22(29.3)$ \\
\hline Lower back & $8(10.3)$ & II (I4.7) & $8(10.3)$ & $16(21.3)$ & $8(10.3)$ & $15(20.0)$ \\
\hline Hip and thigh & $8(10.3)$ & $10(13.3)$ & $4(5.2)^{\mathrm{a}}$ & I8 (24.0) & $4(5.4)$ & $13(17.3)$ \\
\hline Knee & $5(6.4)$ & II (I4.7) & $5(6.4)$ & $16(21.3)$ & $5(6.4)$ & $13(17.3)$ \\
\hline Leg & $8(10.3)$ & $19(25.3)$ & $5(6.5)^{\mathrm{a}}$ & 14 (I8.7) & $6(8.1)$ & 17 (22.7) \\
\hline
\end{tabular}

Notes: aSignificant (increase or decrease) in reported symptoms between baseline and first assessment (McNemar test): ${ }^{b}$ significant (increase or decrease) in reported symptoms between first and second assessment (McNemar test).

EHPP was being conducted, other classes also tended to join in with the experimental group, and showed an interest in the educational video, pamphlet, and posters encouraging children to modify their ergonomic risk elements by sitting properly in class, bringing only books related to the school program that day, and performing exercises to minimize the risk of musculoskeletal pain. In contrast, the control group did not show any increase in ergonomics-related knowledge. Other studies ${ }^{31,32}$ have also shown that short-term interventions can increase children's knowledge about this subject, and are consistent with the findings of our study.

The ergonomic awareness test score also indicates that the ergonomic intervention strategies helped the student remember the ergonomic risks present in the classroom environment and that they could easily answer questions correctly at the first and second assessments. These results are consistent with the theory of education proposed by Egger $^{33}$ that children can remember more interesting items (such as cartoon figures in pamphlets, posters, movies, animation) than can adults. In this study, the EHPP intervention helped to remind students of the ergonomic risks in the classroom environment. Based on the results of the ergonomic awareness

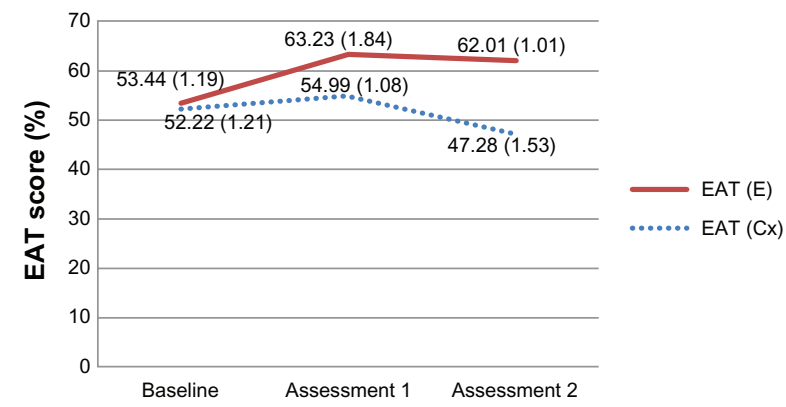

Figure 3 Mean (standard error) EAT score for E group and Cx groups of schoolchildren aged 8 years.

Abbreviations: EAT, ergonomic awareness test; E, experimental; Cx, control. test, a common difficulty was found, ie, incorrect movement patterns and habits become firmly entrenched over the years and are difficult to alter in short-term programs, especially among schoolchildren. This is because the maturity level is different, and learning how the body functions and correct movement patterns is a long process.

As discussed by other researchers, long-term programs are needed to generate indepth behavioral changes in schoolchildren. ${ }^{34}$ In this study, conducting the ergonomic intervention twice was useful for generating behavioral change. Other research has shown that in the wake of a shortterm intervention program, children's knowledge concerning these subjects increased. ${ }^{26}$ Inappropriate posture is largely attributable to the modern sedentary lifestyle, not only in the school environment, but also in many other daily activities, and existing programs are only aimed at proper sitting posture during school lessons. Preliminary investigations in schoolchildren show that watching television and using a computer can increase the risk of developing musculoskeletal pain. ${ }^{8}$ Researchers have estimated that the risk of schoolchildren developing musculoskeletal pain is two-fold higher for those watching television or using a

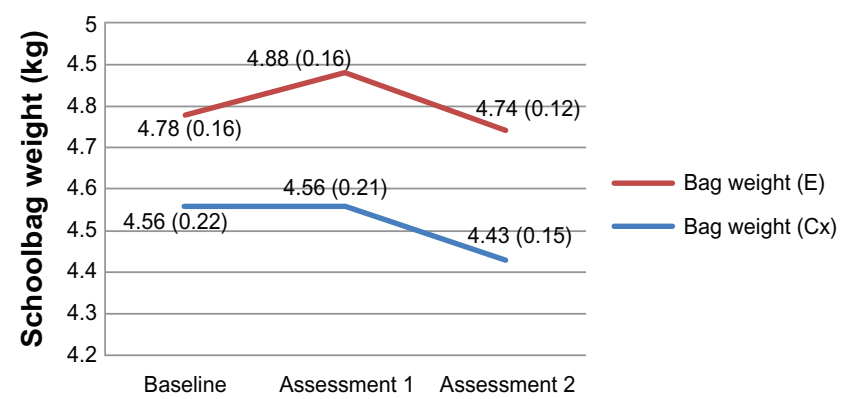

Figure 4 Mean (standard error) schoolbag weight for E group and Cx groups of schoolchildren aged 8 years.

Abbreviations: E, experimental; Cx, control. 


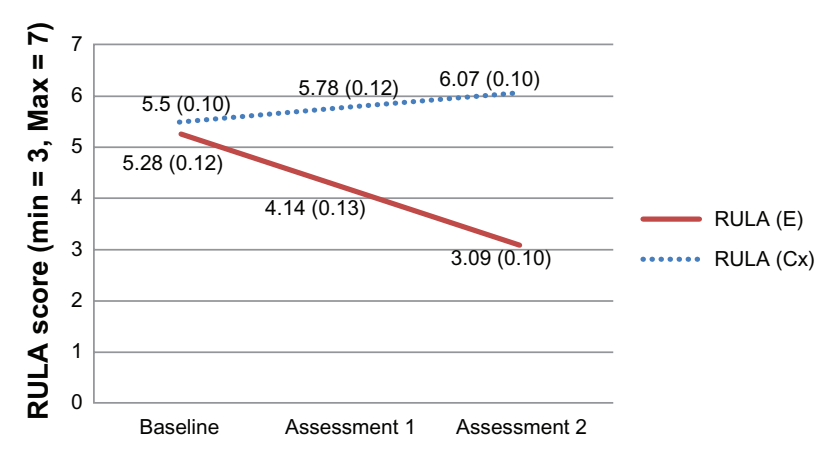

Figure 5 Mean (standard error) RULA score between E and Cx groups of schoolchildren aged 8 years.

Abbreviations: RULA, rapid upper limb assessment; E, experimental; Cx, control.

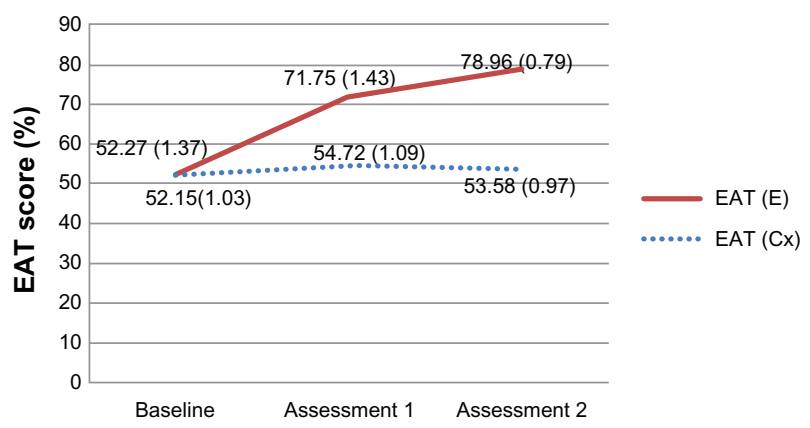

Figure 6 Mean (standard error) EAT score between E and Cx groups of schoolchildren aged II years.

Abbreviations: EAT, ergonomic awareness test; E, experimental; Cx, control.

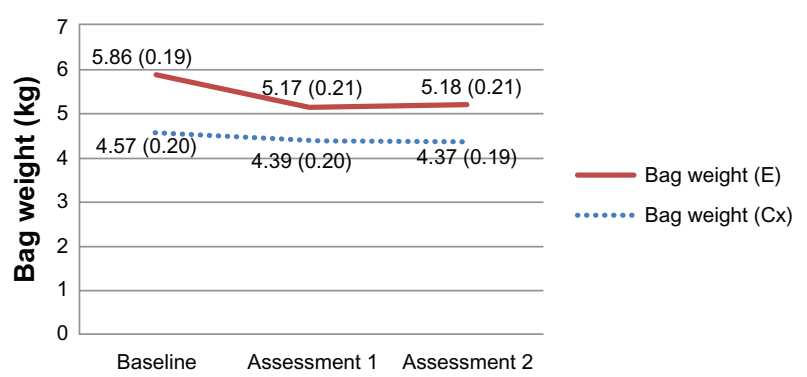

Figure 7 Mean (standard error) schoolbag weight between $E$ and $C x$ groups of schoolchildren aged II years.

Abbreviations: E, experimental; Cx, control.

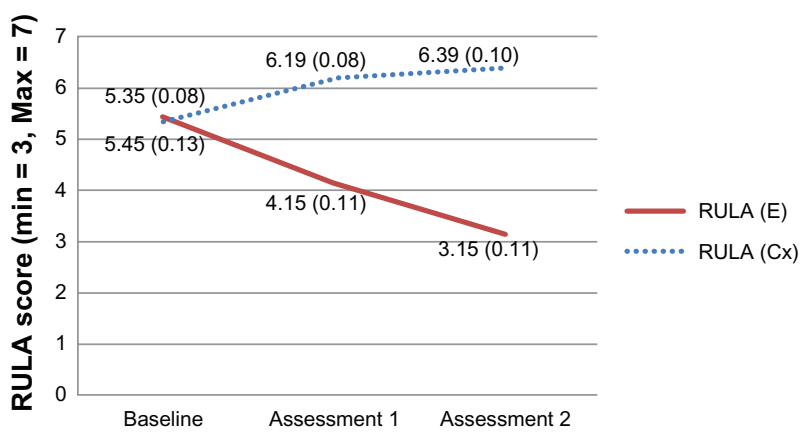

Figure 8 Mean (standard error) RULA score between E and Cx groups of schoolchildren aged II years.

Abbreviations: RULA, rapid upper limb assessment; E, experimental; Cx, control. computer for more than 2 hours a day than for those who spent less time on these activities. ${ }^{8,26}$

Our findings show that the best and most practical approach for educating schoolchildren about ergonomic risk is through modern visual aids and graphics. The design of the pamphlet, video, and poster was based on the architectural information approach, with some adjustment of the graphic design to motivate and stimulate using information on ergonomic risk control. Previous studies $^{35}$ have shown a significant increase in overall knowledge and attitudes after intervention, regardless of whether a physical education component is included. In addition, Ismail et $\mathrm{al}^{25}$ have shown a significant reduction in ergonomic risk after the introduction of an intervention program, namely, intervention in furniture design and health promotion.

\section{RULA score}

The two groups showed a significant difference in RULA score between baseline and the first and second assessment. The RULA scores for the experimental group showed a significant reduction in children aged 8 and 11 years after the second assessment. The change in RULA score from 5 to 4 is a good indicator that the EHPP intervention successfully altered sitting posture. Significant differences were also observed between the intervention and the control groups. However, other studies suggest that ergonomic furniture has more ability to modify sitting behavior., ${ }^{3,25}$ A previous study ${ }^{9}$ provided baseline data on hazard identification and risk assessment, and a risk control study showed a significant association between furniture-related factors and anthropometry. Common symptoms in the study reported by Nurul et $\mathrm{al}^{9}$ included neck, low back, and hand pain. This suggests that the main component of risk in the normal school environment is mismatch between furniture and the dimensions of the body. Nurul et al also reported a baseline RULA score in the range of 5 to 6 . In contrast, our control group showed a significant increase in RULA score among students aged 8 and 11 years after the intervention program at the first and second assessment. This study suggests that the ergonomic risks in the current classroom environment may become a major issue in the future without appropriate intervention.

Our results show that the EHPP intervention program can reduce the RULA score, which helps reduce the risk of incorrect posture. Similar observations were made by Pillastrini et $\mathrm{al}^{36}$ in a different target group showing the ergonomic intervention to be effective in improving spinal 
and upper extremity work-related posture, as well as in the reduction of musculoskeletal complaints, particularly in the shoulders, neck, and lower back.

RULA scores were reduced in the experimental group, indicating that the ergonomic risk had been reduced. The EHPP was tested in this study, and its major components concerning ergonomic risk awareness were identified. Similar results were also obtained by Heyman and Dekel, ${ }^{26}$ in which the two most important components of ergonomics education in schools were identified to be movement and posture. In our study, the EHPP was integrated with the approach taken by Heyman and Dekel ${ }^{26}$ in which several exercises were introduced to reduce muscle fatigue. Movements included exercises for the neck and lower back when sitting in the class and during recess, while another EHPP component included correct sitting posture on a conventional chair. Correct sitting posture includes maintaining the lumbar curve with the neck straight and the overall trunk located in a neutral position, as suggested by Saarni et $\mathrm{al}^{37}$ and Troussier et al. ${ }^{38}$

\section{Schoolbag weight}

No statistically significant difference was observed between the schoolbag weight data at baseline and at the first assessment in the experimental group for students aged 11 years. However, after the EHPP intervention program (which asks students to follow a correct and precise timetable, only bringing books related to the study program for any given day and not bringing other items), schoolbag weight decreased significantly from a mean of $5.86 \pm 1.22 \mathrm{~kg}$ to $4.24 \pm 1.32 \mathrm{~kg}$ in the experimental group. However, it is acknowledged that the EHCC program may not have a lifelong impact on schoolchildren. According to Ismail et al, ${ }^{25}$ furniture intervention strategies are more successful in reducing the risk of carrying a heavy schoolbag. The results of this study also indicated that the storage area was a major factor in efforts to reduce schoolbag weight, as suggested in previous research. ${ }^{1}$ Research has suggested that a significant reduction in schoolbag weight occurs when furniture is used for storage purposes. ${ }^{25}$ This suggests that ergonomic furniture design for Malaysian schoolchildren should consider storage areas, especially with a locking system for their desk drawer. Use of a desk without proper storage, equipped with only a drawer, can lead to students bringing an excessive number of books to school on a daily basis. Therefore, a simple mechanism to reduce the ergonomic risk of schoolbag weight is using a lockable drawer as the main bag storage area.

\section{Reducing ergonomic risk and musculoskeletal pain}

From this study, the reported lifetime prevalence of musculoskeletal pain in the control group was significantly higher than in the experimental group, especially for the neck, shoulder and leg. We also found a lower percentage $(19.2 \%-34.7 \%)$ of neck pain as compared with a previous study by Mohd et al ${ }^{13}$ who reported neck pain was the most prevalent musculoskeletal disorder among schoolchildren (37.3\%), followed by upper back pain (22.7\%) and lower back pain (13.3\%). This study also found a significant difference in shoulder and leg pain reported by the experimental and control groups. Pain at these body sites has been reported to be common in school children due to lifting heavy schoolbags ${ }^{8,13}$ and participation in sports that lead to injury. ${ }^{8,9}$ However, our study showed a lower prevalence of thigh pain than in the study by Yanto et $\mathrm{al}^{39}$ who reported that many school children $(>30 \%)$ in Indonesia aged 11 and 12 years complain of thigh pain.

The prevalence of neck pain decreased from $19.2 \%$ to $15.8 \%$ in the experimental group by the end of the study period. A similar observation was made in a study by Heyman and Dekel ${ }^{26}$ who reported a reduction of symptoms by more than $5 \%$ in a group receiving an exercise intervention as compared with a control group. From this study, we noted other anatomic sites that also showed a reduction in reported pain symptoms ie, the elbow (6.4\% to $3.9 \%)$, arm $(6.5 \%$ to $2.7 \%)$, upper back (10.3\% to $4.1 \%)$, hip and thigh $(10.3 \%$ to $5.2 \%)$, and leg $(10.3 \%$ to $6.5 \%)$. According to our results, the EHPP intervention program was able to reduce musculoskeletal pain significantly in students in the experimental group.

The greatest number of complaints in our intervention study were in the neck, upper back, and low back pain. Jones et $\mathrm{al}^{20}$ concluded that musculoskeletal pain complaints may relate to childhood somatic symptoms. In a study by Mikkelsson et al, ${ }^{40} 30.5 \%$ of children reported headache at least once a week compared with $54 \%$ of children in our study who reported musculoskeletal pain.

Because our study focuses on risk reduction, the intervention in the experimental group showed that EHPP could reduce ergonomic risk among schoolchildren. Our results also show that reducing RULA scores could be done in a cost-effective manner throughout the health promotion program. However, a previous study suggests that reducing schoolbag weight and raising awareness of ergonomic risk could be achieved most economically using ergonomically designed furniture. ${ }^{25}$ 
Educational materials include health promotion packages, which contain exercises to reduce the occurrence of musculoskeletal pain and muscle fatigue among schoolchildren, as suggested by Jones et al. ${ }^{41}$ Results from the present study show that there were some important strategies that can be implemented to rectify heavy schoolbags and poor posture, by implementing strength testing in schoolchildren as suggested by Iyer. ${ }^{42}$ Aside from improving the poor posture adopted by schoolchildren, our research suggests increasing awareness of this issue among school teachers, as recommended by a previous study. ${ }^{43}$

\section{Study limitations}

The main limitation of this study is that it was a short-term intervention study and only focused on certain factors (ie, knowledge of ergonomic risk, schoolbag weight, and posture score) identified in previous studies..$^{21}$ The intervention was very short and considered the rate of changes (ergonomics awareness test, RULA, and bag weight) over a few months because of limitations of access and permission given by school authorities. This particular study only considered three factors, ie, changes in an ergonomics awareness test, RULA score, and schoolbag weight, potentially contributing to musculoskeletal pain. Additional posture assessments should be carried out for all subjects in the future.

\section{Study recommendations}

For future research, it is important to recognize the influence of psychological and family factors on children, especially with regard to the onset of musculoskeletal pain. It would be helpful to understand these risk factors better, as well as the interactions that may exist to ascertain the relative importance and predictive ability of back pain ${ }^{44,45}$ in schoolchildren. While it may be possible to influence physical risk factors in the school environment, it is important that psychological factors are also included in a preventative strategy aimed at reducing the occurrence of musculoskeletal pain amongst schoolchildren. Because this research is the first of its kind in Malaysia, more studies relating to ergonomic risk factors and musculoskeletal pain should be conducted in school children and young adults to prevent injury during their adult years. Ergonomic risk assessment should be conducted frequently when new risks emerge in the school environment, such as new furniture or a new indoor classroom environment. Finally, further research is recommended to examine the relationship between sitting posture and pain reported at various sites in the spine. Unsuitable school furniture may contribute to onset of pain, and those children with psychological and physical difficulties may continue to develop long-term and serious musculoskeletal pain.

\section{Conclusion}

This study shows that ergonomic risk factors for musculoskeletal pain can be modified using the EHPP, which consists of exercises, demonstrations, and training on ergonomic risk awareness, and that these changes are effective in improving body posture in the school environment.

\section{Acknowledgments}

The researchers wish to thank the headmasters of the schools which participated in this research, as well as Pn Hayati, Pn Norida, and Mr Ibrahim for allowing access to the schools and assisting in the data collection process. Special thanks is also extended to Professor Norlijah, Dean of the Faculty of Medicine and Health Sciences, Associate Professor Sharifah Zainiyah, Head of the Community Health Department, Ardiana Naim, Science Officer, and Miss Syahidatussyakirah Katis for assisting with this study, which was funded by the Universiti Putra Malaysia Research University Grant Scheme (RUGS) vote number 91128.

\section{Disclosure}

The authors report no conflicts of interest in this work.

\section{References}

1. Murphy SD, Buckle P. The occurrence of back pain in schoolchildren and the risk factors in schools: Can they be measured? Presented at the Triennial Congress of the International Ergonomics Association and 44th meeting of the Human Factors and Ergonomics Society, July 29-August 4, San Diego, CA. 2000. Available from: http://www.iea.cc/ergonomicss4children/pdfs/ iea2003murphy.pdf. Accessed May 7, 2009.

2. Murphy S, Buckle P, Stubbs D. Classroom posture and self-reported back and neck pain in schoolchildren. Appl Ergon. 2004; 35(2): 113-120.

3. Saarni L, Nygård C-H, Kaukiainen A, Rimpelä A. Are the desks and chairs at school appropriate? Ergonomics. 2007;50(10):1561-1570.

4. Kavitha M, Jalaludin J, Abdah Md A, Zarida H, Shamsul BMT, Syazwan AI. Human sputum interleukin-6 by exposure to $\mathrm{PM}_{10}$ among bus drivers in Klang Valley. J App Sci (Faisalabad). 2010;10(4):269-276.

5. Syazwan AI, Juliana J, Norhafizalina O, Azman ZA, Kamaruzaman J. Indoor air quality and sick building syndrome in Malaysian buildings. Glob J Health Sci. 2009,1(2):127-135. Available from: http://www.ccsenet.org/ journal/index.php/gjhs/article/view/3946. Accessed September 9, 2011.

6. Shaharuddin MS, Nor Kidahus M Mohd, Sumarlan Y, et al. Dental fluorosis (DF) and its relationship with fluoride levels in drinking water in three states in Malaysia. Res J Med Sci. 2010;4(1):20-24.

7. Qaiyum MS, Shaharudin MS, Syazwan AI, Muhaimin A. Health risk assessment after exposure to aluminium in drinking water between two different villages. Journal of Water Resource and Protection. 2011;3(4): 268-274.

8. Syazwan AI, Tamrin SBM, Hassim Z. The association between ergonomic risk factors, RULA score and musculoskeletal pain among school children: a preliminary result. Glob J Health Sci. 2009;1(2):73-84. Available from: http://www.ccsenet.org/journal/index.php/gjhs/article/ viewFile/3301/3476. Accessed July 20, 2011. 
9. Nurul Asyikin MA, Shamsul BMT, Mohd Shahrizal D, Mohamad Azhar MN, Mohd Rafee B, Zailina H. Neck, shoulder, upper and lower back pain and associated risk factors among primary school children in Malaysia. Journal of Medical Safety. 2009;2:37-47.

10. Grimmer K, Williams M. Gender-age environmental associates of adolescent low back pain. Applied Ergonomics. 2000;31(4):343-360.

11. Negrini S, Carabalona R. Backpacks on! Schoolchildren's perceptions of load, associations with back pain and factors determining the load. Spine. 2002;27(2):187-195.

12. Motmans RREE, Tomlow $\mathrm{S}$, Vissers $\mathrm{D}$. Trunk muscle activity in different modes of carrying schoolbags. Ergonomics. 2006;49(2):127-138.

13. Mohd AK, Zailina H, Shamsul BMT, Nurul AMA, Mohd AMN, Syazwan AI. Neck, upper back and lower back pain and associated risk factors among primary school children. J App Sci. 2010;10(5): 431-435.

14. Bygrave S, Legg SJ, Myers S, Llewellyn M. Effect of backpack fit on lung function. Ergonomics. 2004;47(3):324-329.

15. Balague F, Nordin M, Skovron ML, Dutoit G, Yee A, Waldburger M. Non-specific low-back pain among schoolchildren: a field survey with analysis of some associated factors. J Spinal Disord. 1994;7(5): 374-379.

16. Yeats B. Factors that may influence the postural health of schoolchildren (K-12). Work. 1997;9(1):45-55.

17. Troussier B, Davoine P, De Guademaris R, Fauconnier J, Phelip X. Back pain in school children. A study among 1178 pupils. Scand $J$ Rehabil Med Suppl. 1994;26(3):143-146.

18. Harreby M, Nygaard B, Jessen T, et al. Risk factors for low back pain in a cohort of 1389 Danish school children: An epidemiologic study. Eur Spine J. 1999;8(6):444-450.

19. Kristjansdottir G, Rhee H. Risk factors of back pain frequency in schoolchildren: a search for explanations to a public health problem. Acta Paediatr. 2002;91(7):849-854.

20. Jones GT, Watson KD, Silman AJ, Symmons DPM, Macfarlane GJ. Predictors of low back pain in British schoolchildren: A populationbased prospective cohort study. Pediatrics. 2003;111(4):822-828.

21. Stratton G. Promoting children's physical activity in primary school: An intervention study using playground markings. Ergonomics. 2000; 43(10):1538-1546.

22. Salminen JJ, Oksanen A, Maki P, Pentti J, Kujala UM. Leisure time physical activity in the young. Correlation with low-back pain, spinal mobility and trunk muscle strength in 15-year-old school children. Int J Sports Med. 1993;14(7):406-410.

23. Vikat A, Rimpelä M, Salminen JJ, Rimpelä A, Savolainen A, Virtanen SM. Neck or shoulder pain and low back pain in Finnish adolescents. Scand J Pub Health. 2000;28(3):164-173.

24. Nurul Asyiqin MA, Shamsul BMT, Mohd Shahrizal D, et al. Development of ergonomics furniture for primary school in Malaysia. Alam Cipta. 2009;4:17-28.

25. Ismail SA, Tamrin SBM, Norr MAM, et al. Evaluation of two ergonomics intervention programs in reducing ergonomic risk factors of musculoskeletal disorder among school children. Res J Med Sci. 2010; 4(1):1-10.

26. Heyman E, Dekel H. Ergonomics for children: an educational program for elementary school. Work. 2008;31(2):253-257.

27. Dockrell S, Fallon E, Kelly M, Masterson B, Shields N. School children's use of computers and teachers' education in computer ergonomics. Ergonomics. 2007;50(10):1657-1667.

Journal of Pain Research

\section{Publish your work in this journal}

The Journal of Pain Research is an international, peer-reviewed, open access, online journal that welcomes laboratory and clinical findings in the fields of pain research and the prevention and management of pain. Original research, reviews, symposium reports, hypothesis formation and commentaries are all considered for publication.

Submit your manuscript here: http://www.dovepress.com/journal-of-pain-research-journal
28. Mandal AC. Correct height of school furniture. Hum Factors. 1982;24(3):257-269.

29. Kuorinka I, Jonsson B, Kilbom A, et al. Standardised Nordic questionnaires for the analysis of musculoskeletal symptoms. Appl Ergon. 1987;18(3):233-237.

30. McAtamney L, Nigel Corlett E. RULA: a survey method for the investigation of work-related upper limb disorders. Appl Ergon. 1993;24(2):91-99.

31. Schwartz RK, Jacobs K. Body basics: a cognitive approach to body mechanics training in elementary school back pain prevention programs. Work. 1992;2:53-60.

32. Balagué F, Nordin M, Dutoit G, Waldburger M. Primary prevention, education, and low back pain among school children. Bull Hosp Jt Dis. 1996;55(3):130-134.

33. Egger G. Health Promotion Consultant's Instruction Manual 2004. New South Wales: Spring; 2006:25-27.

34. Cardon G, De Clercq D, De Bourdeaudhuij I, Breithecker D. Sitting habits in elementary schoolchildren: a traditional versus a "moving school." Patient Educ Couns. 2004;54(2):133-142.

35. Heyman E, Dekel H. Ergonomics for children: an educational program for physical education students. Paper presented at the 16th World Congress on Ergonomics, 10-14 July, 2006, Maastricht, The Netherlands.

36. Pillastrini P, Mugnai R, Farneti C, et al. Evaluation of two preventive interventions for reducing musculoskeletal complaints in operators of video display terminals. Physical Therapy. 2007;87(5):536-544.

37. Saarni LA, Rimpelä AH, Nummi TH, Kaukiainen A, Salminen JJ, Nygård C-H. Do ergonomically designed school workstations decrease musculoskeletal symptoms in children? A 26-month prospective follow-up study. Appl Ergon. 2009;40(3):491-499.

38. Troussier B, Tesniere C, Fauconnier J, Grison J, Juvin R, Phelip X. Comparative study of two different kinds of school furniture among children. Ergonomics. 1999;42(3):516-526.

39. Yanto ES, Herlina HS, Baba MDD. Mismatch between school furniture dimensions and student's anthropometry: a cross-sectional study in an elementary school, Tangerang, Indonesia. Proceedings of the Ninth Asia Pacific Industrial Engineering and Management Systems Conference. Nusa Dua, Bali, Indonesia December 3-5, 2008

40. Mikkelsson M, Salminen JJ, Kautiainen H. Non-specific musculoskeletal pain in preadolescents. Prevalence and 1-year persistence. Pain. 1997;73(1):29-35.

41. Jones MA, Stratton G, Reilly T, Unnithan VB. Recurrent non-specific low-back pain in adolescents: The role of exercise. Ergonomics. 2007; 50(10):1680-1688.

42. Iyer SR. An ergonomic study of chronic musculoskeletal pain in schoolchildren. Indian J Pediatr. 2001;68(10):937-941.

43. Storr-Paulsen A. "Kroppen med i skolen" - et skole-ryg-projekt [The body and the school: a study describing back pain in relation to school.] Ugeskr for Laeger. 2003;165(1):37-41. [Danish.]

44. Nicolaou A, Nicholson B, Hans G, Brasseur L. Outcome predictors for treatment success with $5 \%$ lidocaine medicated plaster in low back pain with neuropathic components and neuropathic pain after surgical and nonsurgical trauma. $J$ Pain Res. 2011;4:25-38.

45. Jorge LL, Feres CC, Teles VEP. Topical preparations for pain relief: Efficacy and patient adherence. J Pain Res. 2011;4:11-24.

\section{Dovepress}

The manuscript management system is completely online and includes a very quick and fair peer-review system, which is all easy to use. Visit http://www.dovepress.com/testimonials.php to read real quotes from published authors. 